\title{
P02.58. The feasibility of integrating ear acupuncture into the aeromedical evacuation system from Ramstein Air Base (Germany) to Andrews Air Force Base (US)
}

\author{
J Walter ${ }^{1 *}$, A York ${ }^{1}$, S Thati ${ }^{1}$, R Niemtzow ${ }^{2}$, S Burns $^{2}$ \\ From International Research Congress on Integrative Medicine and Health 2012 \\ Portland, Oregon, USA. 15-18 May 2012
}

\section{Purpose}

Recently, military leaders have endorsed the need for holistic, non-pharmacologically based approaches to pain. Acupuncture has been shown to be an effective adjunctive therapy for specific pain conditions; however, acupuncture has occupied only a marginal role in pain management. We investigated what would happen if a simple ear acupuncture procedure was introduced into the medical care delivered in the aeromedical evacuation system to wounded warfighters being evacuated from Germany to the US.

\section{Methods}

Volunteers were recruited among military personnel being evacuated from Germany to the U.S. who reported pain. Five semi-permanent needles were placed in each ear just prior to flight. Pain scores were recorded at intervals during and at the end of the flight. Patient satisfaction scores and medication use were measured. Medical personnel provided information on provider satisfaction. Needles were removed upon landing.

\section{Results}

With advance preparation and training of personnel, the administration of an ear acupuncture procedure did not interfere with the normal pre-flight preparation process. A larger, randomized controlled clinical trial aimed at assessing effectiveness of ear acupuncture is possible. Fifty percent reported being mostly satisfied and 21\% were very satisfied with the ear acupuncture treatment.
Sixty-two percent reported they would elect to receive the ear acupuncture treatment again for pain relief. There was a significant decrease $(\mathrm{p}<0.0001)$ in pain levels (avg. pre-treatment pain rate $=4.07$; post-flight pain rate $=2.76$ ). No significant difference was detected between participants who reported taking pain medications and those who did not therefore both groups (medication takers and non-takers) experienced similar decreases in pain levels.

\section{Conclusion}

The potential of acupuncture to deliver pain relief with minimal side effects in this population is worth further investigation, especially if it may mitigate the overuse of pain medication with its inherent risks and challenges. We will discuss the challenges of conducting research in this environment and the details of the results.

\section{Author details \\ ${ }^{1}$ Samueli Institute, Alexandria, USA. ${ }^{2}$ U.S. Air Force, Andrews AFB, USA.}

Published: 12 June 2012

doi:10.1186/1472-6882-12-S1-P114

Cite this article as: Walter et al:: P02.58. The feasibility of integrating ear acupuncture into the aeromedical evacuation system from Ramstein Air Base (Germany) to Andrews Air Force Base (US). BMC Complementary and Alternative Medicine 2012 12(Suppl 1):P114.

${ }^{1}$ Samueli Institute, Alexandria, USA

Full list of author information is available at the end of the article

( 2012 Walter et al; licensee BioMed Central Ltd. This is an Open Access article distributed under the terms of the Creative Commons 